\title{
Scanning nanocalorimetry at high cooling rate of isotactic polypropylene
}

\author{
Felice De Santis, ${ }^{* \dagger}$ Sergey Adamovsky, ${ }^{\ddagger}$ Giuseppe Titomanlio, ${ }^{\dagger}$ Christoph Schick ${ }^{\ddagger}$ \\ ${ }^{\dagger}$ Department of Chemical and Food Engineering, University of Salerno, 84084 Fisciano (SA), Italy; \\ ${ }^{\ddagger}$ Institute of Physics, University of Rostock, 18051 Rostock, Germany
}

* CORRESPONDING AUTHOR E mail: fedesantis@unisa.it

A synoptic table of the experiments and the figures showing all results of cooling scans (Figures S1, S2, S3, S4, S5) and subsequent melting behaviors (Figures S6, S7, S8, S9, S10). Two 3D plots (Figures S11, S12): the former shows the cooling scans and the latter shows the subsequent melting behaviors. 
Table S1. Performed tests (cooling rate in bold means that the thermograms are also reported in Figure 5 or in Figure 7 of the article, for the cooling scans and for the subsequent heating scans respectively).

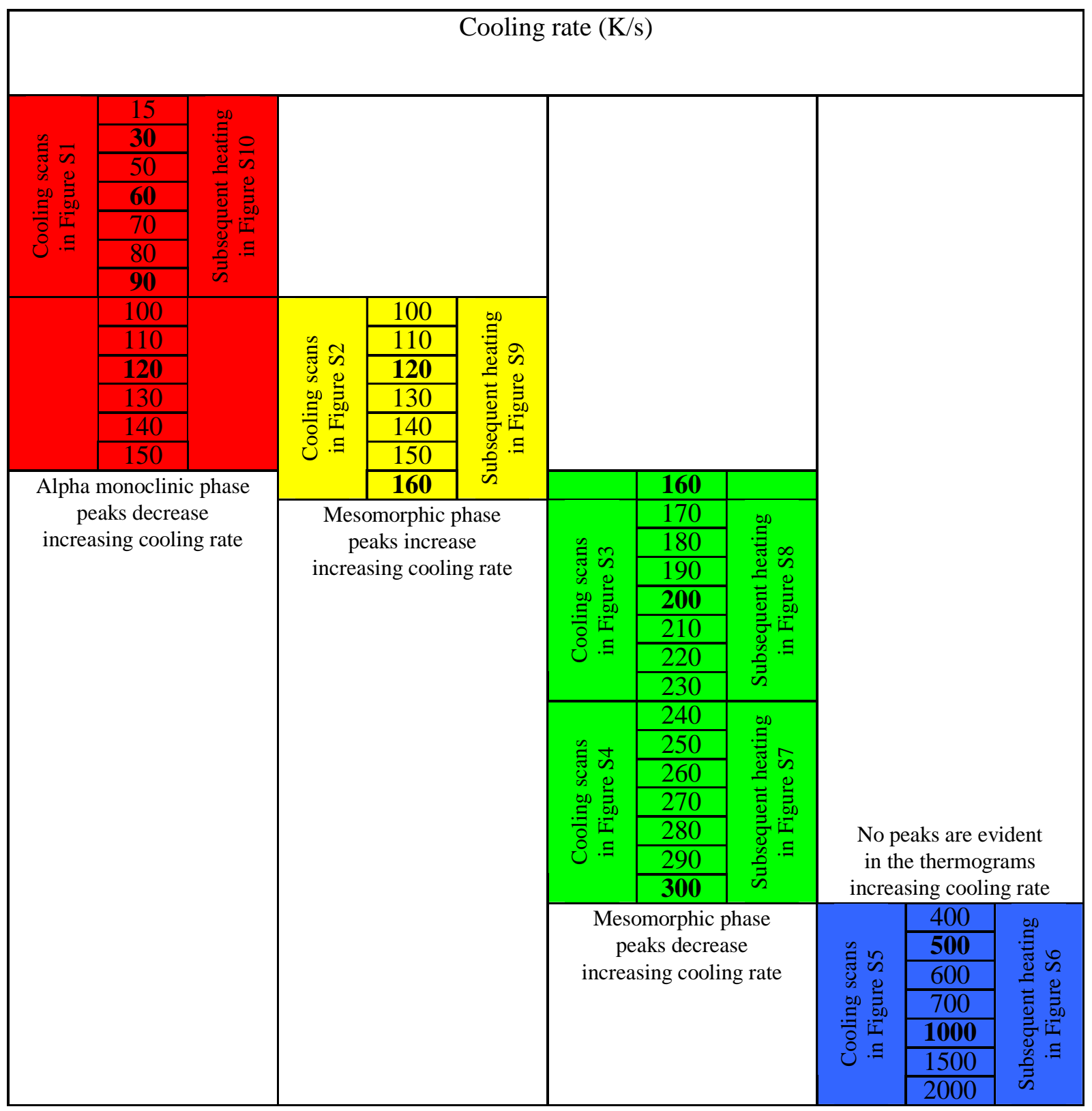




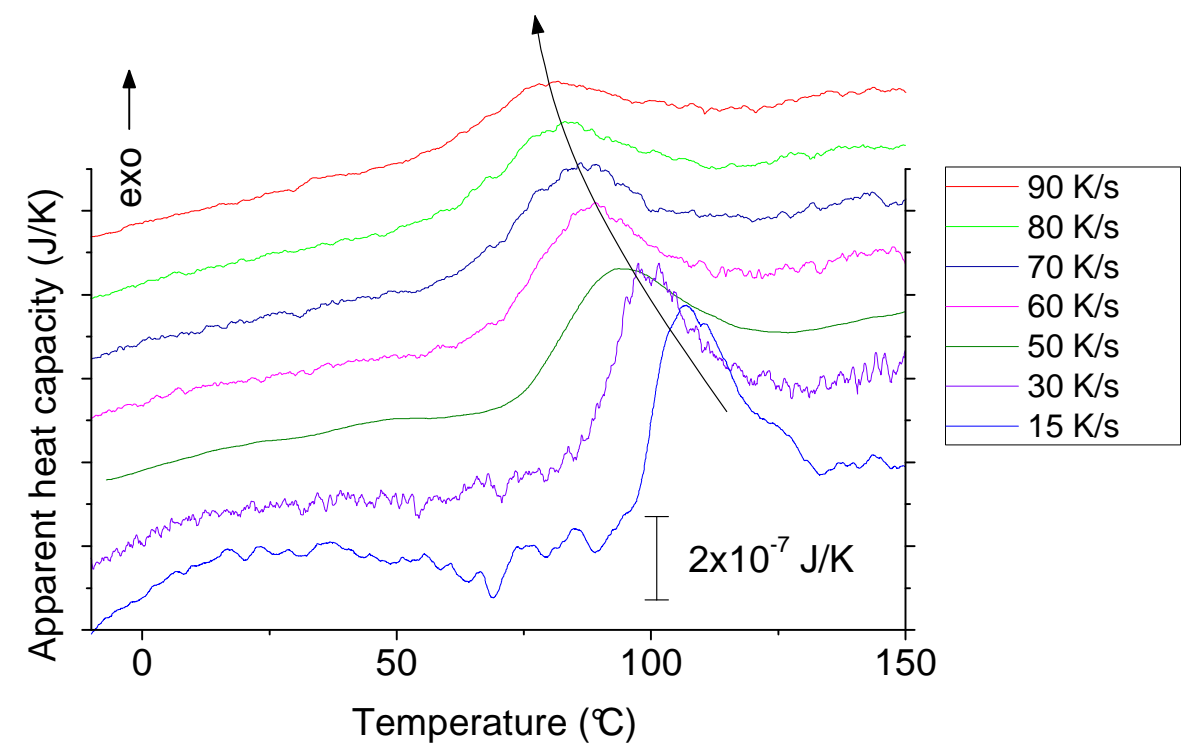

Figure S1. Thermograms of i-PP sample at different cooling rates $(15 \div 90 \mathrm{~K} / \mathrm{s})$ from 210 to $-15^{\circ} \mathrm{C}$.

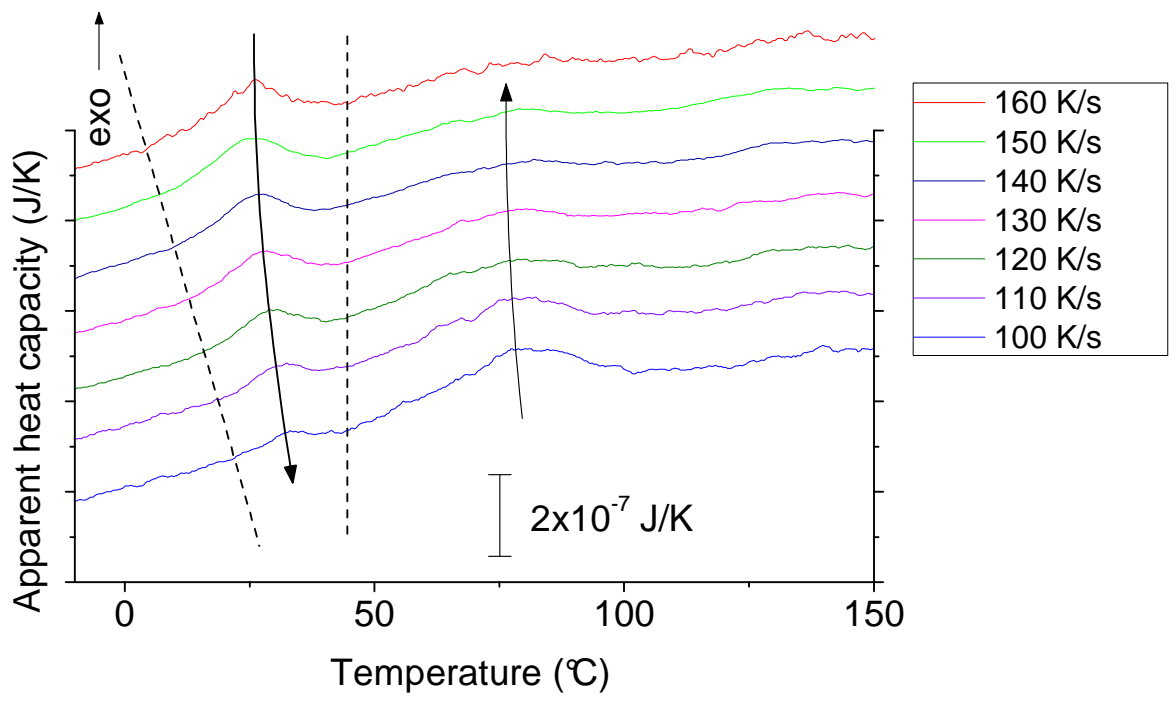

Figure S2. Thermograms of i-PP sample at different cooling rates $(100 \div 160 \mathrm{~K} / \mathrm{s})$ from 210 to $-15^{\circ} \mathrm{C}$. 


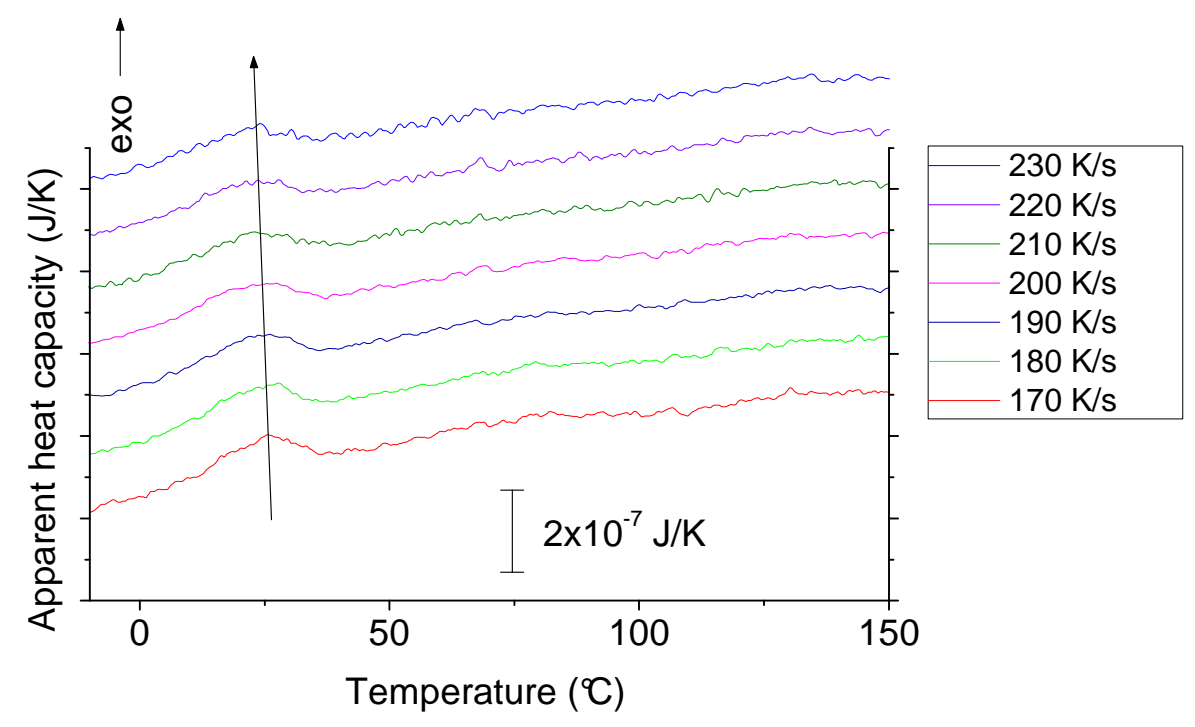

Figure S3. Thermograms of i-PP sample at different cooling rates $(170 \div 230 \mathrm{~K} / \mathrm{s})$ from 210 to $-15^{\circ} \mathrm{C}$.

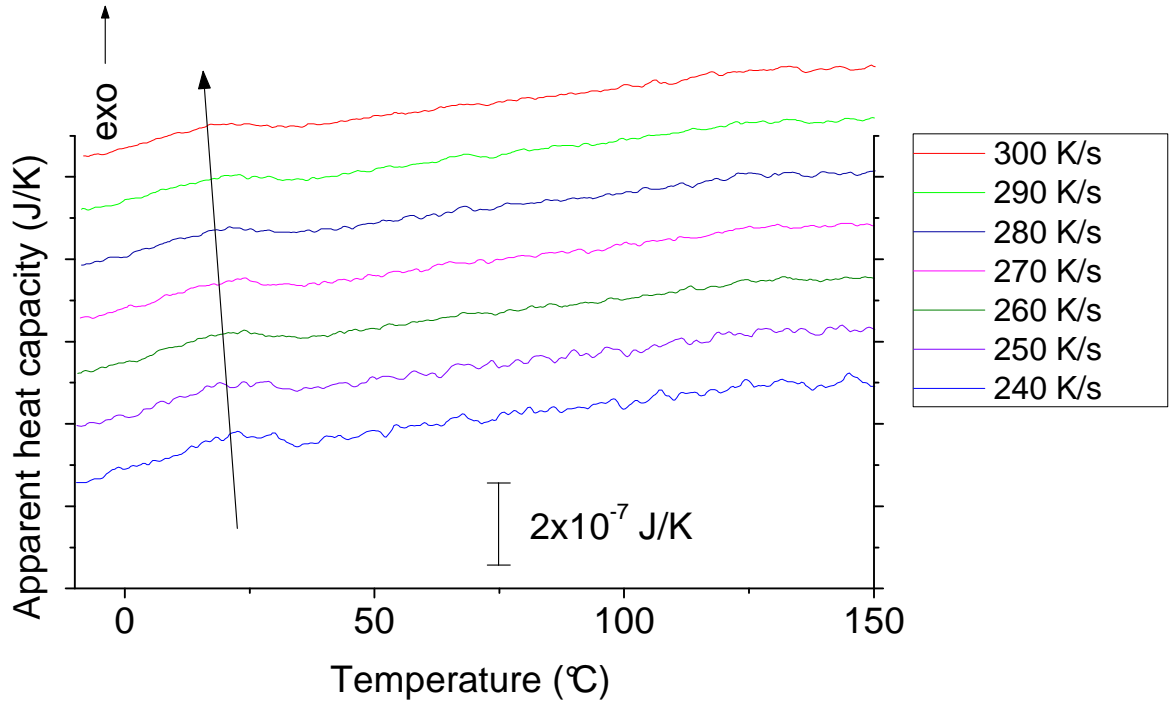

Figure S4. Thermograms of i-PP sample at different cooling rates $(240 \div 300 \mathrm{~K} / \mathrm{s})$ from 210 to $-15^{\circ} \mathrm{C}$. 


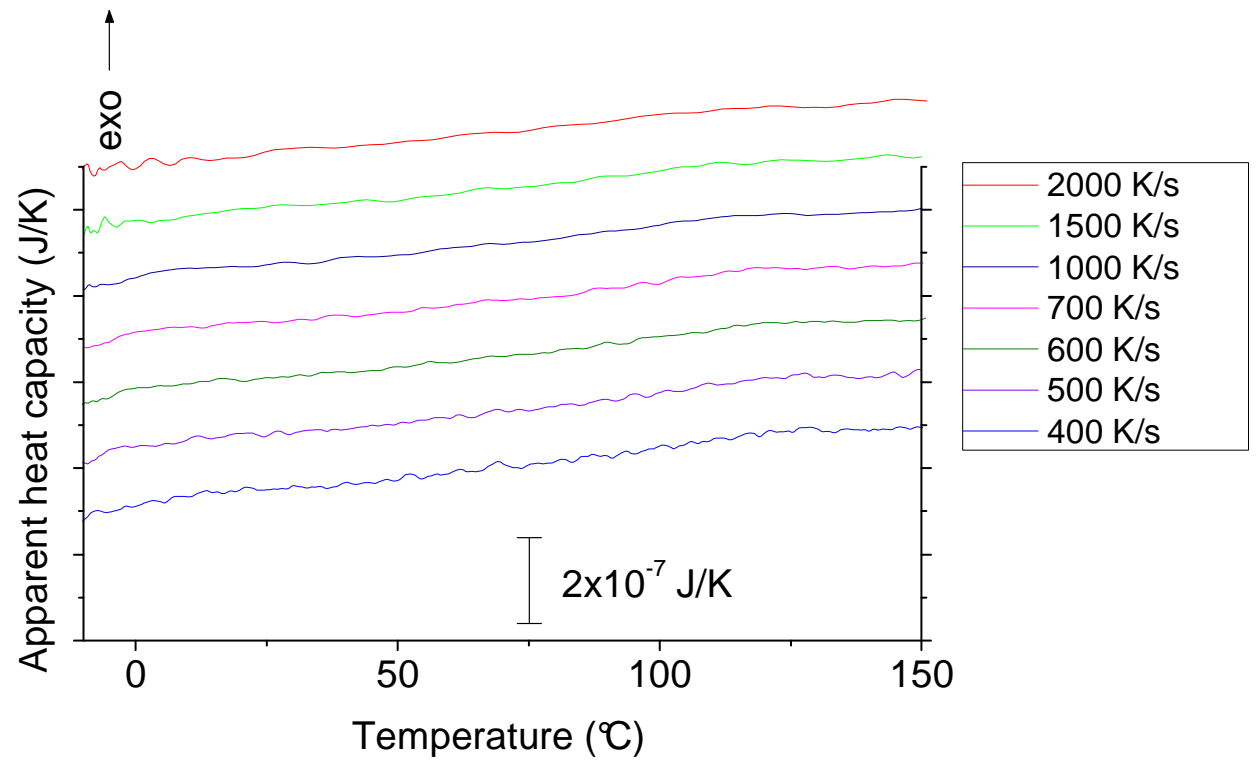

Figure S5. Thermograms of i-PP sample at different cooling rates $(400 \div 2000 \mathrm{~K} / \mathrm{s})$ from 210 to $-15{ }^{\circ} \mathrm{C}$.

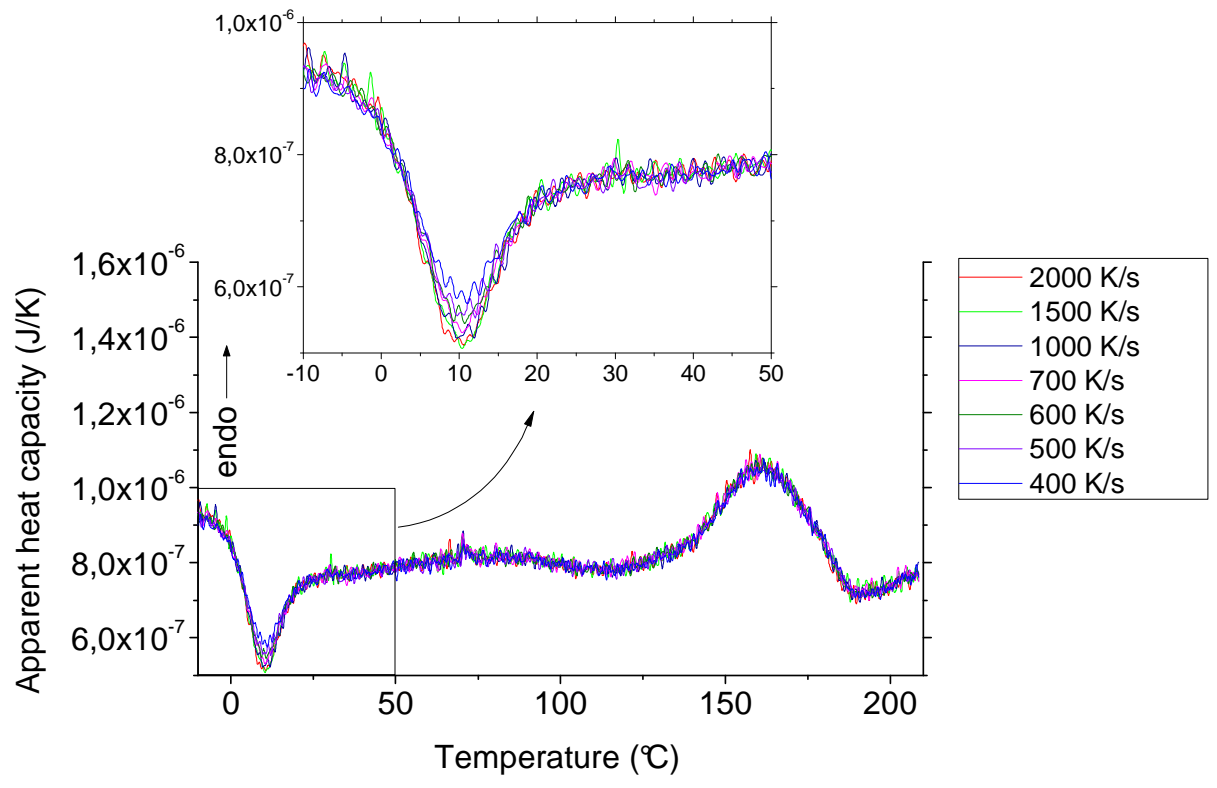

Figure S6. Thermograms of i-PP sample at different cooling rates $(400 \div 2000 \mathrm{~K} / \mathrm{s})$ from 210 to $-15{ }^{\circ} \mathrm{C}$. 


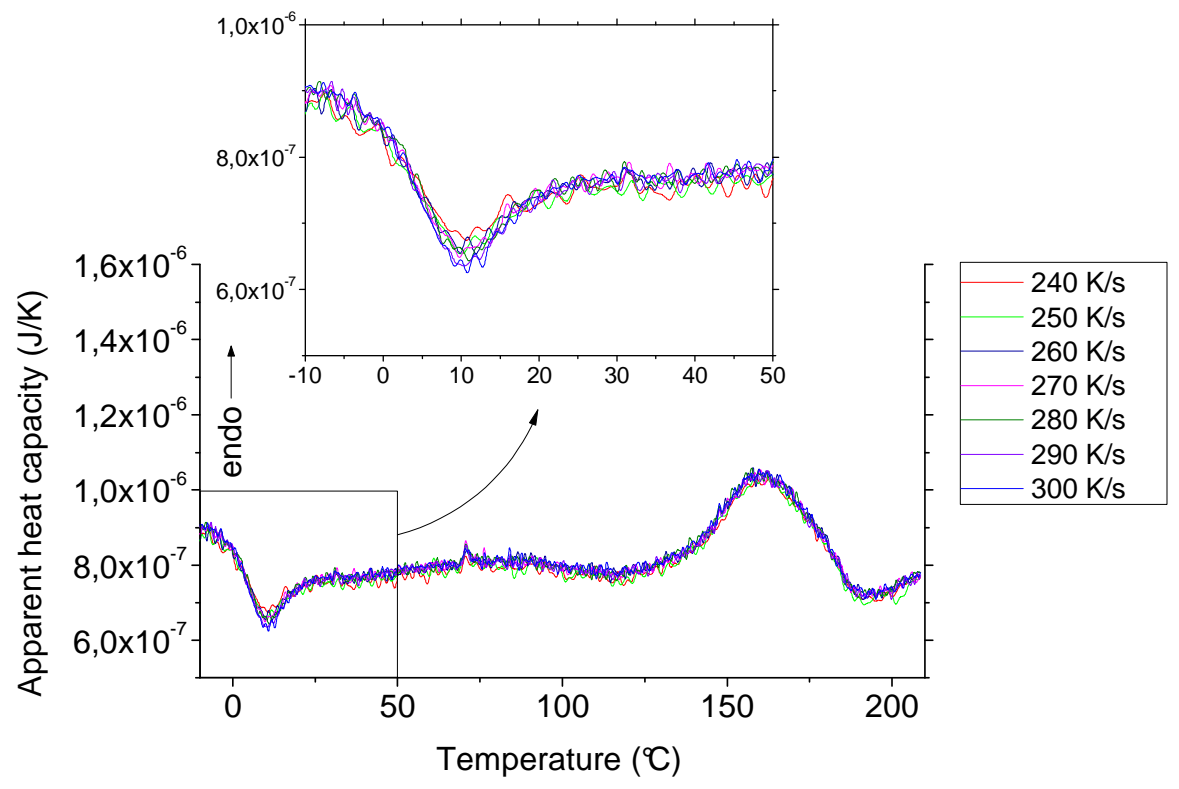

Figure S7. Thermograms of i-PP sample at a heating rate of $50 \mathrm{~K} / \mathrm{s}$.

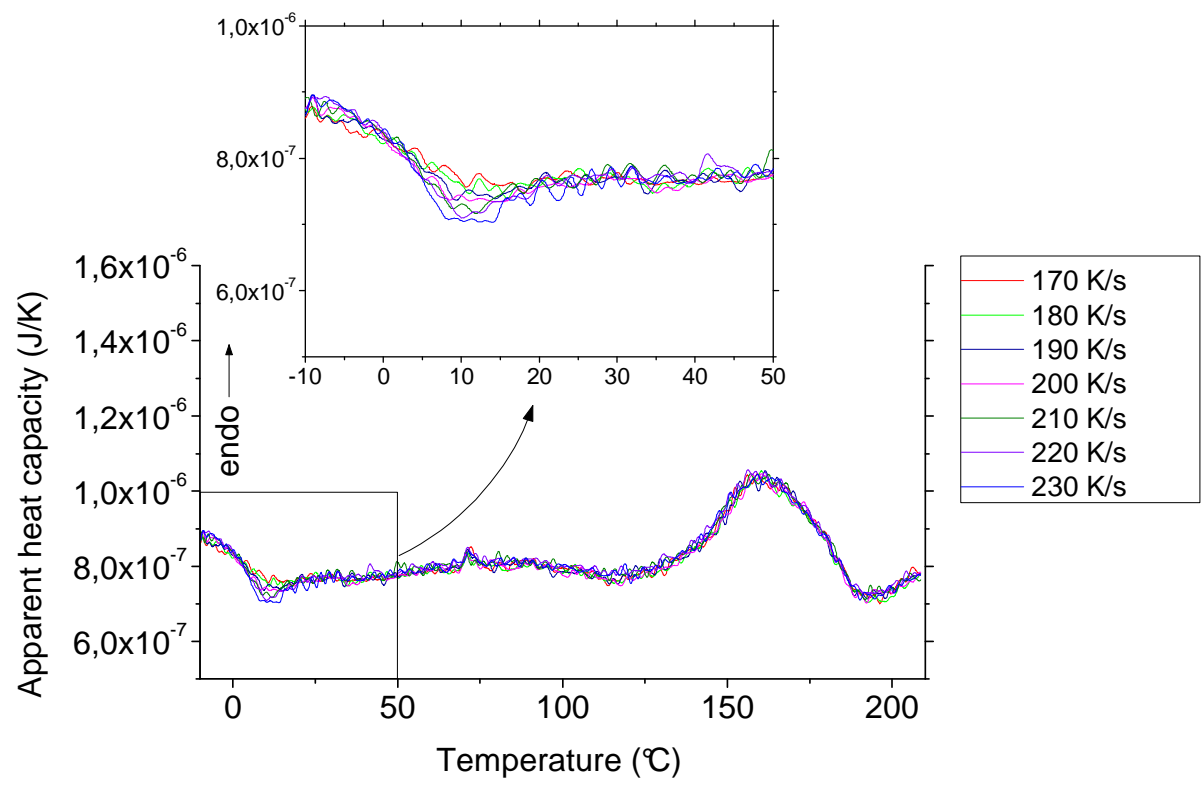

Figure S8. Thermograms of i-PP sample at a heating rate of $50 \mathrm{~K} / \mathrm{s}$. 


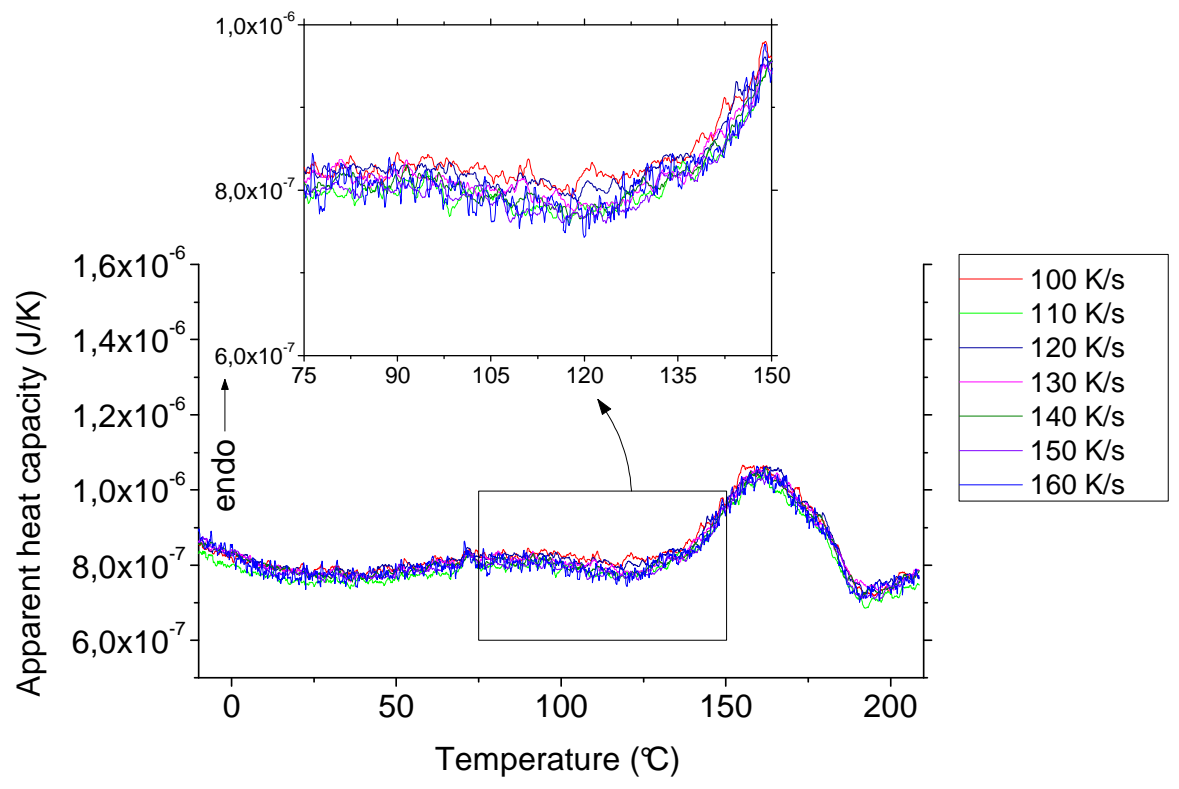

Figure S9. Thermograms of i-PP sample at a heating rate of $50 \mathrm{~K} / \mathrm{s}$.

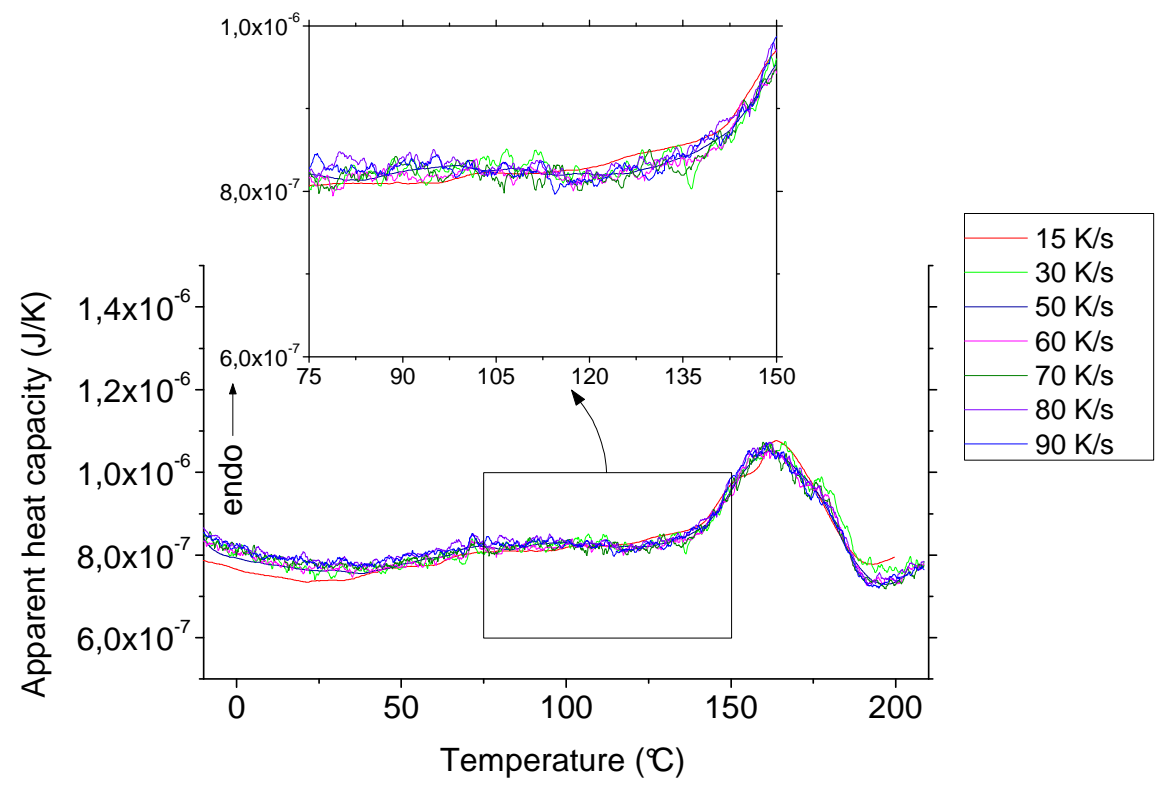

Figure S10. Thermograms of i-PP sample at a heating rate of $50 \mathrm{~K} / \mathrm{s}$. 


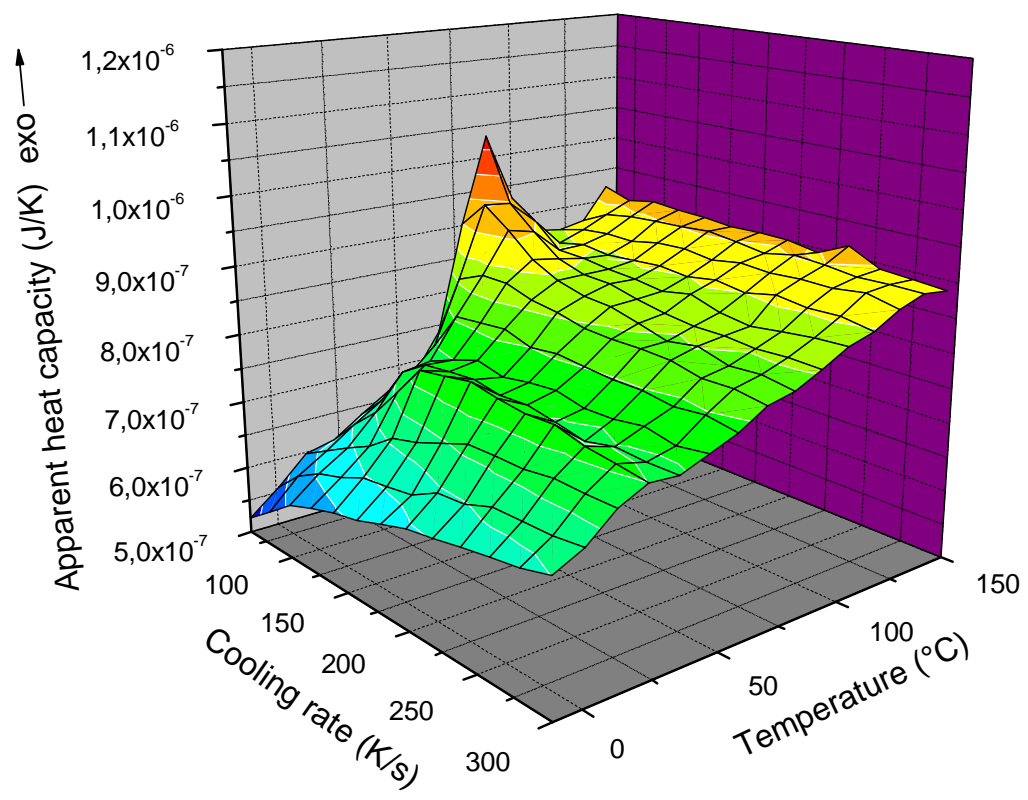

Figure S11. Thermograms of i-PP sample at several cooling rates $(60 \div 300 \mathrm{~K} / \mathrm{s})$.

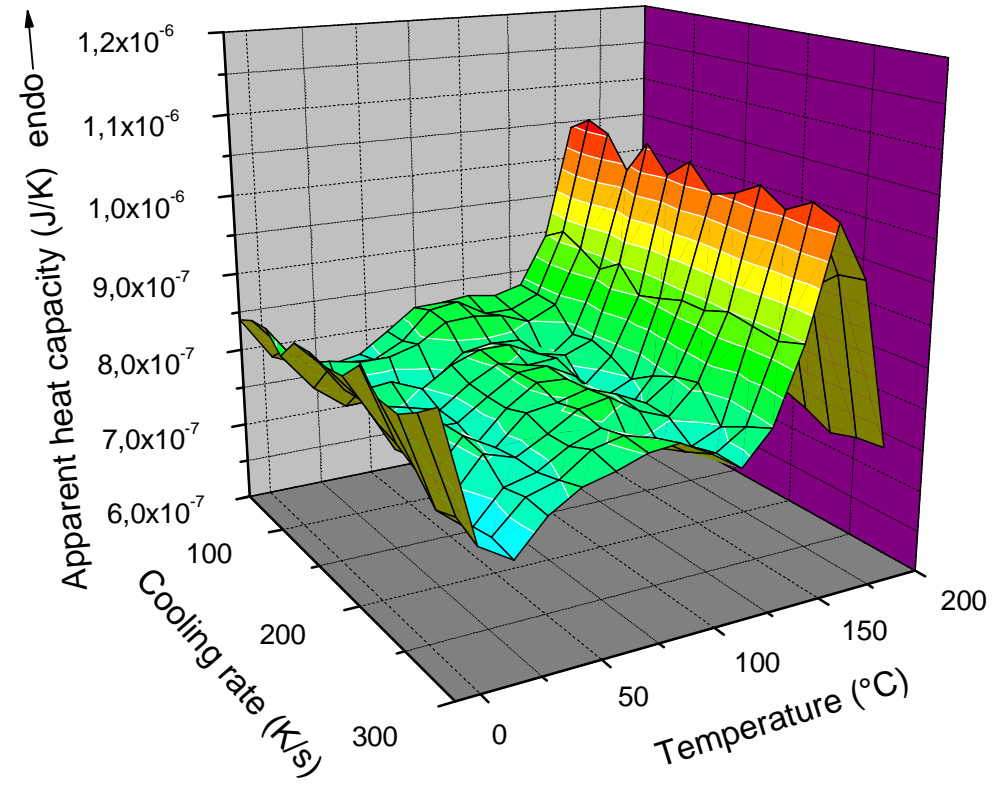

Figure S12. Thermograms of i-PP sample (solidified with cooling rates ranging in the interval $60 \div 300 \mathrm{~K} / \mathrm{s}$ ) at a heating rate of $50 \mathrm{~K} / \mathrm{s}$. 